\title{
Reflexões e inquietudes sobre design: aspectos da linguagem e da pedagogia do Desenho Industrial
}

\author{
Thoughts and concerns about Design: aspects related to language \\ and pedagogy of Industrial Design
}

SILVA, Danilo Emmerson Nascimento I

Universidade Federal de Pernambuco I danilo.emmerson@gmail.com

\begin{abstract}
Resumo
O desenho industrial - design - brasileiro completou meio século de existência. Durante este período sofreu transformações como qualquer fenômeno social: ampliou suas fronteiras; expandiu seus mercados; desenvolveu-se pedagogicamente; assumiu novas responsabilidades; adotou novas denominações; adaptou métodos exógenos à sua realidade. Enfim, amadureceu enquanto área do conhecimento e profissão. Entretanto, algumas questões da linguagem e da pedagogia precisam ser repensadas e revistas com maior profundidade.
\end{abstract}

Palavras-chaves: desenho industrial, design, linguagem do design, pedagogia do design.

\section{Abstract}

Brazilian industrial design - design - is nearing completion of a half century of existence. During this time, it has undergone transformations, like any social phenomenon. It has broadened its horizons, expanded its markets, developed pedagogically, taken new responsibilities, adopted new names, and adapted exogenous methods to its reality. Finally, it has matured both as a field of knowledge and profession. However, some issues of language and pedagogy must be revised and reviewed in greater depth.

Keywords: industrial design; design; design language; design pedagogy. 


\section{INTRODUC̣ÃO}

A área do Desenho industrial no Brasil, recentemente adotada por Design, completou meio século de implantação, contabilizando-se o período de sua primeira inserção no ensino superior com a Escola Superior de Desenho Industrial (ESDI), em 1963, no Rio de Janeiro: um modelo alemão importado da Hochschule fur Gestaltung (HfG), da cidade de Ulm, segundo Souza (1996). Deste marco em diante, criaram-se muitos outros cursos em todas as regiões do país. O ensino na pós-graduação, nos níveis de lato e de stricto sensu, também tem atingido níveis nunca visto antes. O número de profissionais lançados ao mercado e egressos de cursos de nível técnico, tecnológico, e bacharelado de instituições novas ou antigas também demonstra outra estatística que depõe a favor da área. A titulação dos profissionais tem aumentado consideravelmente seja quanto à Especialização, ao Mestrado, ao Doutorado e ao Pós-Doutorado. As regiões de maior tradição industrial no país, verificadas entre a Sudeste e a Sul, refletem o número de cursos superiores bastante discrepante às demais. Embora, as regiões Centro-Oeste, Nordeste e Norte têm registrado um aumento de oferta de cursos na área significativo se comparadas a outras décadas anteriores. Em algumas cidades se pode constatar que a profissão e a área tem notório conhecimento e reconhecimento da sociedade. Entretanto, noutras é parcial ou totalmente desconhecida.

Entretanto, mesmo depois destes dados favoráveis e do crescimento verificado da área - ainda que de modo irregular e não uniforme devido às próprias características continentais do país - existem algumas questões que não foram bem solucionadas ou totalmente resolvidas. Sempre fazem parte do cotidiano, das reflexões e dos encontros entre os profissionais da área.

A primeira delas tem a ver com a mudança da expressão Desenho Industrial para Design. Gomes (1989) assegura que esta mudança, de fato, se desencadeou durante o encontro sobre $O$ Ensino do desenho Industrial para os Anos 90, ocorrido em Florianópolis, estado de Santa Catarina onde reuniu pelo menos um representante das 26 instituições de ensino superior do país daquela época. A Carta de Canasvieiras foi o documento gerado pelo grupo contendo cerca de "trinta e três recomendações ou propostas para a correção da trajetória do ensino do design do século XXI", Gomes (1989, p.142-143). Uma destas intenções foi a própria mudança na nomenclatura.

Àquela época, cursava Desenho Industrial pela Universidade Federal de Pernambuco. Recorda-se da celeuma que este fato gerou. Vários estudantes, profissionais e docentes não concordavam com esta adoção e repudiavam como o fato se desencadeou. Parece ter sido uma mudança arbitrária, sem uma consulta ou uma discussão aprofundada nos diversos fóruns da área e que envolvesse a parcela totalizadora de profissionais atuantes, todos os docentes das IES (Instituições do Ensino Superior) e os discentes daquela época. Pode até ter havido algumas discussões pontuais e esporádicas, mas decididamente parecia não refletirem a decisão do universo global dos diretamente envolvidos e 
interessados. O próprio ex-professor Luiz Vidal Negreiros Gomes, um dos grandes pensadores do design no Brasil, autor de vários artigos e livros sobre Desenho Industrial e temáticas correlatas, entre outros, foi um defensor ferrenho, tanto da manutenção do termo, mas também da adoção de palavras no idioma português em vez da adoção por termos anglicistas. Gomes nas diversas obras tem mostrado, desde àquela época, as implicações que isto acarretaria no futuro. Uma delas, estaria intimamente associada com a temática de seu doutoramento cujo objetivo norteava o fato de se rever a tecnologia, a praxiologia, a taxonomia, a metrologia, a axiologia, a filosofia, a epistemologia, a história, a pedagogia e a linguagem do design visando a melhoria e a modernização das estruturas curriculares, das técnicas dos educadores, dos objetivos educacionais e, por conseguinte, a capacitação dos futuros profissionais.

Este ensaio ${ }^{1}$ retoma e aprofunda, em particular, os aspectos da linguagem e da pedagogia na área do Desenho Industrial - Design - no Brasil.

\section{A LINGUAGEM NA ÁREA DO DESIGN}

Freyre (1961, p.125) retratou que a desorganização sócio-econômica e o desequilíbrio da relação homem com o meio entre os indígenas da América se deu a partir da intromissão dos Europeus nestas terras principiando a degradação de uma raça dita atrasada com o contato da adiantada.

Ao continuar tal leitura, voltando-se a memória há alguns séculos atrás, fatalmente será visualizada a cena dos índios "bestificados" com a presença dos brancos e seus modernos equipamentos. Ainda hoje, essa cena de bestificação está presente também nas fisionomias não mais como vaga lembrança e, sim, sob forte expressão, por exemplo, ao se deparar com as maravilhas que a tecnologia dos países ditos "desenvolvidos" proporciona no dia a dia.

O Brasil, em quase todos os estágios de seu desenvolvimento, parece ter servido a outras nações como ancoradouro aos movimentos trazidos e importados de países primeiro-mundistas: infelizmente, a cultura dos brasileiros, ainda que rica, exuberante e inigualável, aparenta possuir certo teor de submissão.

Já frisou Redig (1993, p.13) quando tentou explicar a falta da importância merecida à cultura material no Brasil que a desconsideração pelo objeto por parte dos profissionais e pela sociedade se justifica pela própria história da cultura material brasileira importada desde a Colônia até os dias atuais. 
Mas em se pretendendo amenizar a culpa e retirar-se o peso da consciência a todo esse processo de dependência, pode-se dizer que isto se denominaria por vício $^{2}$ e, de certo modo, todos estariam "viciados". Pede-se perdão por aqueles que se sintam ofendidos. A tentativa da melhor explicação desta metáfora segue adiante!

Embora esse vício já perdure durante séculos no meio cultural e tecnológico, jamais será tarde para se começar a mudar a visão tecnológica e cultural de uma sociedade. Pode-se partir, então, da premissa de que se deve adotar o tratamento, pois para um diagnóstico de vícios há tratamentos específicos. Analogamente a qualquer processo de "cura" se faz necessário primeiro a aceitação e, depois, programar a ação. Dentre os costumes e práticas típicas da suposta submissão reside um dos maiores vícios brasileiros e que também se apresenta nas mais variadas atividades: trata-se do emprego corriqueiro do idioma inglês - sendo mais uma demonstração clara da idolatria, aprisionamento e dependência dos brasileiros por iniciativas de origens estrangeiras.

Inquestionável é a importância do idioma inglês, principalmente, na atualidade projetual. Conhecer e falar fluentemente este idioma, entre outras vantagens, pode significar a abertura de portas, inclusive, oportunidades associadas a emprego. Mas, por outro lado, percebe-se que o uso do inglês tem se tornado abusivo, banalizado, vulgarizado e, quase sempre, sem necessidade, passível de justificação, embora não se justifica, somente por razão publicitária e mercadológica.

Tal conflito linguístico bastante propagado, certamente, pelos meios de comunicação de massa atinge desde as classes sociais mais baixas até mesmo aquelas com maiores níveis educacionais e instrucionais, a saber, os diversos setores de mercado tanto quanto os centros universitários e de pesquisa. Parece um paradoxo! Mas aqueles meios, educacionalmente falando, mais favorecidos também estão aderindo a esta nova tendência. Algo que se lastima e com o qual se deve preocupar urgentemente! Um ponto é saber falar inglês e utilizarse desse idioma corretamente nos lugares e momentos convenientes; outro ponto é poluir visual e oralmente o cenário brasileiro que nos rodeia. Presenciase, corriqueiramente, na televisão, nos jornais, nas revistas, nas ruas, fachadas de prédios, muros, seminários, congressos, palestras, entre outros, qualquer oportunidade, torna-se ideal ao bombardeio dos anglicismos e, o que é bem pior, eventualmente, empregos grosseiros como a grafia e a contextualização das palavras erradas os quais não levam a lugar algum, a não ser servir de ironias quanto ao desconhecimento do idioma inglês.

2 A palavra vício, em dicionários, no sentido a que se propõe, parece indicar definições associadas a grande defeito ou imperfeição; mau hábito; defeito que torna uma pessoa ou objeto impróprios para aquilo a que se destinavam; tendência habitual para certo mal; hábito de proceder mal; costume condenável ou censurável; hábito prejudicial. Portanto, neste ensaio a palavra vício refere-se restritamente aos vícios de linguagem. 
Esta experiência similar aconteceu quando cursava Desenho Industrial, pela UFPE entre o período de 1989 a 1993. Naquela época, aos dezenove anos de idade, fascinado com a entrada em um curso superior, já havia sentido a primeira decepção, diga-se assim, na universidade: percebera a exaustiva tentativa de alguns lecionadores em defenderem tudo que descendia dos países estrangeiros, principalmente, pertencentes à Europa e América do Norte, a começar pelo uso de termos anglicistas como Design, Designer, Industrial Design, Know-how, High Tech dentre outros, e a continuar com a bestificação das tecnologias exógenas em detrimento às endógenas. Indiscutivelmente, por ter uma mãe, professora do idioma português, não poderia encarar os fatos de modo diferente.

Apesar dos tenros anos e do pouco nível de conhecimento qualquer atitude ou questionamento estudantil contrária à academia se configurava sobre tais aspectos inadmissíveis e desrespeitosos quanto aos professores mestres, doutores, com outras titulações ou, até mesmo, à coordenação do próprio curso, embora se acreditasse que este raciocínio se apresentava de modo coerente de acordo com as raízes e contexto em que se estava inserido.

Recorda-se que pouco se foi consultado sobre esta mudança. A geração que vivenciou esta mudança não pôde participar em sua plenitude de um debate aberto, sem medo de represálias, seguido, por exemplo, de uma votação democrática em fóruns da área. O fator mais agravante foi alguns poucos decidirem por muitos não apenas como se mudaria a nomenclatura da área, mas, sobretudo, sem haver uma preocupação com as gerações que carregariam tal legado de maneira contrariada. Quem optou por fazer um processo seletivo vestibular, e, por conseguinte, exercer uma profissão de Desenho Industrial, decididamente, não escolhera por design, nem teve alternativa para isto.

Percebera àquela época, por exemplo, o quanto o idioma português é riquíssimo, pois possui todo um alicerce semântico e morfológico para não se precisar nem recorrer a termos estranhos. Se, por ventura, as palavras faltarem como correspondentes de outras línguas poder-se-ia, eventualmente, criar uma nova palavra - é para isto que existem os neologismos - valendo, contudo, salientar: fundamentada no idioma português. Para tal, imaginava-se: deve haver uma versatilidade enorme, embora se pareça algo complicado. O que causava maior segurança e confiança advinha do fato de se presenciar, de tempos em tempos, publicações e reedições atualizadas dos dicionários brasileiros contendo uma infinidade de palavras, termos, neologismos, expressões novas, entre outras, com o intuito de acompanharem as mudanças que a sociedade sofre.

Buscando explicações e entendimento para estes acontecimentos, diversos questionamentos rondavam sempre deixando, diga-se de passagem, inconformado com os fatos: Perguntava-se: i) Será que para uma área tão importante como esta não haveria oportunidade ou espaço para a inserção de termos portugueses novos ou até mesmo voltar-se a empregar e adotar aqueles mais antigos? Ou então, questionava-se: ii) Qual a resistência que há em se continuar empregando os anglicismos no discurso gráfico-verbal? iii) Por qual 
motivo outras áreas não adotam termos estrangeiros, nesse caso, anglicistas para designarem suas profissões?

Àquela época, o professor e pesquisador Gomes (1993) já dava os primeiros passos para a reeducação dos profissionais na importância do emprego de termos da língua portuguesa durante a atividade projetual, mais especificamente, de produtos. Esclarecia categoricamente inclusive propondo a adoção do termo Desenho: [...] "A falta dessa terminologia do Desenho tem causado uma comunicação confusa, impossibilitando que as definições do Desenho sejam bases para modificações, com verdadeiras mudanças, neste vasto e amplo campo educacional" (GOMES, 1993, p.10).

Começava-se, então, a compreender que não se pensava equivocadamente nem poderia estar fora de sintonia com a maneira nada habitual de encarar estes fatos. A primeira obra de Gomes (1993) funcionou como uma prova contundente contra os discursos contrários e serviu para fundamentar ou exercitar a modesta oratória de alguns estudantes daquela época.

Tão logo, encontrava-se a visualização de como funcionavam os empréstimos dos discursos na academia. Aliás, algo bastante proveitoso porque faz com que o pensamento científico evolua e atinja novos patamares do conhecimento. A cadeia do pensamento científico tem, assim, sua continuidade embasada no ciclo retroalimentativo do conhecimento fortemente evidenciado pela revisão da literatura.

A publicação dos trabalhos de cunho científico, por exemplo, faz com que o ciclo mantenha sua continuidade necessária.

O mesmo Gomes (1993, p.22) demonstrava que ao estabelecer uma comparação entre os termos desenhar, desenho e desenhador dentre as três línguas românicas - o Galego, o Castelhano e o Catalão - e a língua irmã portuguesa seriam encontradas semelhanças morfológicas e semânticas entre si.

Mostrou uma relação desses termos e suas correspondências com o inglês, conforme o Quadro 1.

Quadro 1 - O termo Desenho empregado em alguns idiomas

\begin{tabular}{|l|l|l|l|l|}
\hline Português & Galego & Castelhano & Catalão & Inglês \\
\hline Desenhar & Deseñar & Diseñar & Dissenyar & To design \\
\hline Desenho & Deseño & Diseño & Disseny & Design \\
\hline Desenhador & Deseñador & Diseñador & dissenyador & Designer \\
\hline Debuxar & Debuxar & Dibujar & Dibuixar & To draw \\
\hline Debuxo & Debuxo & Dibujo & Dibuix & Drawing \\
\hline Debuxante & Debuxante & Dibujante & Dibuixant & Draughtsman \\
\hline
\end{tabular}

Fonte: Gomes (1993). 
As pessoas as quais não concordavam com esta linha de raciocínio, normalmente uma parcela dos profissionais da área, alegavam que tais termos do português se encontravam em desuso e que, portanto, seriam arcaicos. Mas, parece óbvio! A partir do momento que se introduz palavras estrangeiras aos discursos, logicamente, aquelas nativas ficarão em desuso, obsoletas e arcaicas. Quando não se exercita o atrofiamento é inevitável! [...] "Foi o que parece ter acontecido com o termo Desenho em português. Após a era dos descobrimentos, fase áurea de Portugal, muito se perdeu de sua tradição nas artes e técnicas". (GOMES, 1993, p.20).

Além do mais, este tipo de argumento não se justificava na sua plenitude até mesmo porque se vivencia um período de tentativas de resgate à língua tupi, tão antiga quanto às raízes, mas mesmo assim, há indivíduos preocupados e desejando vê-la nos currículos escolares além de tentar inseri-la na cultura nacional.

Em primeiro lugar, percebe-se a falta da valorização do uso do idioma para identificação da área de desenvolvimento e projeto de produtos; sim, porque se não existir o reconhecimento e o orgulho ou a satisfação, de se dizer isto, ou aquilo outro, com palavras da própria língua natural, de nada adiantaria tal esforço; e, em segundo lugar, precisa-se praticar. Se os profissionais que detêm o espaço para divulgar tais termos retornarem a pô-los em evidência e em seus discursos seja nos congressos, seminários, jornais, televisão, academia dentre outros espaços, estes, se tornarão evidentes e contemporâneos novamente.

Neste sentido, parafraseando Gomes (1996) a grande área dos Desenhos consegue aglutinar a subárea do Desenho Operacional - desenho imitativo, definido e convencional - e, a subárea do Desenho Projetual - desenho de comunicação, de ambiente e de artefato. Ou seja, a palavra em português Desenho tanto possui a possibilidade de aplicação da representação quanto da concepção e planejamento formal. Ainda segundo este autor o fato da longa dependência tecnológica e do subdesenvolvimento dos países da língua portuguesa pode ter determinado a baixa utilização dos significados associados a projeto, concepção, criação, planejamento, plano e outros se mantendo apenas em uso aqueles que se aproximavam de atividades operacionais e instrumentais.

É bem verdade que o termo design e suas variações possuem características atrativas e peculiares a ponto de torná-lo tão difundido e adotado em várias localidades, mas esta mesma adoção parece demonstrar um dos tantos aspectos, que repercutem na vulnerabilidade da cultura tupiniquim às influências externas.

Se for para inserir termos estranhos à língua portuguesa, como realmente se fez no caso de design e designer, porque não se adotaram os termos correspondentes ao galego, ao catalão ou ao castelhano, irmãos da língua portuguesa? Aliás, diga-se de passagem, a sonoridade das palavras correspondentes soa muito bem aos ouvidos. 
Atualmente, depois de algumas décadas de bombardeios anglicistas no ramo projetual, em especial a de produtos e, sua quase que total adoção e preferência pelo emprego do termo design para identificar uma atividade profissional, pode-se levantar a seguinte colocação: por qual motivo os países de língua castelhana não aderiram nem costumam utilizar em seus discursos Design e, sim, Diseño? Do mesmo modo, em vez de Designer continuam a adotar Diseñador. No mínimo, dão mais valor ao seu idioma que os brasileiros. Outras respostas poderiam ser apresentadas, mas se tornaria o discurso repetitivo e enfadonho. Seria interessante que os leitores refletissem e tirassem suas próprias conclusões.

O Quadro 2 demonstra como algumas nações tratam a denominação referente ao desenho industrial com seus respectivos idiomas. 
Quadro 2- Termo Desenho Industrial e equivalências em idiomas.

\begin{tabular}{|c|c|c|}
\hline $\begin{array}{l}\text { Termo em } \\
\text { Português }\end{array}$ & $\begin{array}{l}\text { País ou Nação } \\
\text { (Idioma) }\end{array}$ & Termo Equivalente \\
\hline \multirow{31}{*}{$\begin{array}{l}\text { Desenho } \\
\text { Industrial }\end{array}$} & Espanhol & Diseño Industrial* \\
\hline & Inglês & Industrial Design* \\
\hline & Alemão & $\begin{array}{l}\text { Produkgestaltung ou industrielle Formgebung*; } \\
\text { Industrie-Design** }\end{array}$ \\
\hline & Francês & Esthétique Industrielle* \\
\hline & Italiano & Disegno Industriale* \\
\hline & Russo & $\begin{array}{l}\text { Tecnicheskaia Estetika*; Промышленный } \\
\text { дизайн** }\end{array}$ \\
\hline & Malaio/Indonésio & Reka Bentuk Perindustrian** \\
\hline & Africâner & Industriële Ontwerp** \\
\hline & Albanês & Dizajnit Industrial** \\
\hline & Azerbaijano & S囚naye Dizayn** \\
\hline & Catalão & Disseny Industrial \\
\hline & Crioulo haitiano & Endistriyèl Design** \\
\hline & Croata & Industrijski Dizajn** \\
\hline & Dinamarquês & Industriel Design** \\
\hline & Eslovaco & Priemyselný Dizajn** \\
\hline & Esloveno & Industrijsko Oblikovanje** \\
\hline & Esperanto & Industria Dezajno** \\
\hline & Estoniano & Tööstusdisaini** \\
\hline & Finlandês & Teollinen Muotoilu** \\
\hline & Galego & Disseny Industrial \\
\hline & Galês & Dylunio Diwydiannol** \\
\hline & Holandês & Industrieel Ontwerpen** \\
\hline & Indonésio & Industri Desain** \\
\hline & Islandês & Industrial Design** \\
\hline & Letão & Rūpnieciskais Dizains** \\
\hline & Lituano & Pramoninis Dizainas** \\
\hline & Maltês & Reka Bentuk Perindustrian** \\
\hline & Norueguês & Industrial Design** \\
\hline & Polonês & Wzornictwo Przemysłowe** \\
\hline & Romeno & Design Industrial ** \\
\hline & Sueco & Industriell Formgivning** \\
\hline
\end{tabular}

Como consequência, dessa adoção anglicista, já se pode adiantar algumas situações no cotidiano que têm causado alguns transtornos para a própria área:

A- A adoção do termo design permite que outras profissões e ofícios a se autointitularem também com o termo - a popularização trouxe vários outros profissionais de formação semelhante também 
passaram a se autodenominar designers, a saber, artistas plásticos, decoradores, estilistas e arquitetos, por exemplo;

B- Pela mesma causa, vários profissionais sem nenhuma formação projetual também aderiram à autodenominação de designers, por exemplo, cabeleireiros, costureiras, cozinheiros, micreiros, artesãos, alguns profissionais de nível técnico e outros. Isto reflete uma massiva banalização dos termos;

C- O emprego do design e do designer continua sendo replicado de modo errôneo - com frequência encontra-se a troca dos termos no sentido das frases além da grafia errada como desing, desinger, disaign, disaigner e, assim, sucessivamente.

D- O emprego do termo design pode ter dificultado mais ainda a regulamentação da profissão - isto ocorre pelo aumento da ecletividade da forma de atuação profissional. Se anteriormente esta tentativa da regulamentação não se concretizara com os desenhistas industriais - projetistas de produtos e comunicadores visuais - imagine-se nos últimos anos com a enorme variação e especificidades;

algumas experiências frustrantes vividas por empresários ou empresas que contratam os novos designers tendem a generalizar os problemas para a atividade ou para todos os profissionais;

a simples adoção de estabelecimentos em registrar e acrescentar o termo design, por estar em voga, em sua razão social têm causado confusão no seu funcionamento interno, desde às atribuições de funcionários até à falta de compreensão do negócio por parte dos dirigentes e dos próprios clientes.

Talvez por causa de alguns destes motivos, ainda se encontrem profissionais, escritórios, empresas, órgãos, entidades, institutos, faculdades e cursos que não abdicam do emprego da expressão quase extinta Desenho Industrial. E não significa apenas uma expressão, mas a conotação e a denotação que carrega consigo mesma. No caso de projeto de produtos a indústria (referindo-se ao industrial) estará sempre presente mesmo se for manufatureira, da maquinofatura ou de produções mais limitadas ou artesanais.

Enfim, as reflexões sobre esta problemática, na tentativa da busca de soluções, poderão colher frutos maiores adiante.

Recentemente, em uma das últimas conversas informais, pessoalmente, com o ex-professor e mestre Gomes, eis que este frisou em certo tom de satisfação e do dever cumprido: 


\begin{abstract}
pela Universidade Federal de Pernambuco, outros pela Universidade Federal de Santa Maria e, outros tantos ainda pela editora sCHDs, todos, voltados à educação, ensino e profissão do Desenho Industrial (Desenho) no Brasil, cabe aos interessados, seguirem ou não o caminho a que nos propomos, [transcrição de palavras orais].
\end{abstract}

Sendo assim, nada impede e, tampouco, não há razão ou argumentos plausíveis para não se cogitar, talvez, o reemprego e a readoção dos termos oriundos da língua portuguesa ao se referir, não só à atividade projetual, como também a outras áreas afins, embora se acredite na dificuldade e na passividade de muitos. A língua, os valores, os hábitos, os costumes, a cultura, tudo sofre constantes depreciações por causa de atitudes como aquela: um simples emprego de uma palavra, mas que pode influenciar no mínimo, no nível de dependência e identidade cultural ${ }^{3}$. Talvez, por isso que tudo sofra desvalorização, justamente, porque mesmo os brasileiros não costumam dar valor ao que se tem ao que se é e ao que se pode ser.

Enfim, segundo Gomes (1993, p.19): “[...] A língua é um dos reflexos do estágio de progresso de uma nação". Isto implica afirmar que os desdobramentos e as derivações dos termos tem uma relação direta e proporcional ao desenvolvimento das áreas e profissões.

\title{
A PEDAGOGIA NA ÁREA DO DESIGN
}

Um outro ponto crucial tocante à esta área e profissão diz respeito ao processo educacional e de formação verificado no âmbito das instituições superiores enas grades dos cursos de Design. Whiteley (1998), um dos pensadores do Desenho britânico e assumidade mundial, professor universitário, autor de vários artigos e livros na área, na tentativa de apresentar os modelos de ensino identificados nas inúmeras instituições de ensino da atualidade e respaldado nas grades e matrizes curriculares dos cursos, estabelece uma classificação a partir desta análise, a saber: i) o designer formalizado; ii) o designer teorizado; iii) o designer politizado; iv) o designer consumista; v) o designer tecnológico; e, vi) o designer valorizado.

Para Whiteley (1998, p.63-75), resumidamente, os perfis dos cursos e da formação profissional ficariam assim compreendidos de acordo com as suas denominações no Quadro 3:

3 Recentemente, pensadores como Gui Bonsiepe e Itiro Ilda (2013) têm desenvolvido reflexões, discursos e publicações que tangenciam preocupações como as apresentadas neste ensaio. 
Quadro 3- Classificação de perfis do designer segundo Whiteley

\begin{tabular}{|c|c|}
\hline Perfil & Descrição \\
\hline O designer formalizado & $\begin{array}{l}\text { Aquele gestado sob parâmetros da aplicação prática, } \\
\text { funcionalista e utilitária presente nos materiais, em mét- } \\
\text { odos de construção, de forma e de proporção tão pre- } \\
\text { sentes no período modernista, em especial, no modelo } \\
\text { da Bauhaus; qualquer embasamento e fundamentação } \\
\text { teórica é vista como prejudicial à formação do profis- } \\
\text { sional; esta visão, na atualidade, se aproxima também do } \\
\text { reducionismo do design ao imediatismo proporcionado } \\
\text { pelas ferramentas tecnológicas e informatizadas; }\end{array}$ \\
\hline O designer teorizado & $\begin{array}{l}\text { No outro pólo, em oposição ao formalizado, situa-se este } \\
\text { modelo. Neste caso, a teoria é levada tão a sério que a } \\
\text { prática se torna apenas um detalhe. Este modelo tenta } \\
\text { se justificar com a afirmativa de que toda teoria explica e } \\
\text { fundamenta a prática e que a prática sem a reflexão teóri- } \\
\text { ca não tem respaldo. Este modelo, em doses exageradas, } \\
\text { é tão prejudicial à formação do profissional quanto o an- } \\
\text { terior uma vez que pode se afastar bastante da realidade; }\end{array}$ \\
\hline O designer politizado & $\begin{array}{l}\text { Este modelo tem uma caracterização de formar um } \\
\text { profissional mais crítico, ético, responsável, consciente } \\
\text { de seu papel social e político. Tem suas origens no Con- } \\
\text { strutivismo e no Produtivismo russos a partir de } 1917 \text {. } \\
\text { Recebeu outras assepções na década de } 1970 \text { com Pap- } \\
\text { anek e a responsabilidade social do designer. na década } \\
\text { de } 1980 \text { incorporou o perfil ambientalista. E, na década } \\
\text { de } 1990 \text {, incorporou o discurso ético do prossional de } \\
\text { design. Este modelo, apesar da sua louvável contribuição } \\
\text { à formação do profissional, por vezes, se torna utópico e } \\
\text { ingênuo, pois acredita cegamente que os consumidores } \\
\text { agem racionalmente nas suas decisões; }\end{array}$ \\
\hline O designer consumista & $\begin{array}{l}\text { Neste caso, a formação do profissional encontra-se sin- } \\
\text { tonizado apenas às variações, as tendências, modismos, } \\
\text { estilos ou qualquer artifício que justifique o consumo, o } \\
\text { aumento das vendas, as leis do mercado. Em geral, neste } \\
\text { caso, se torna apolítico, e tenta se justificar com o discur- } \\
\text { so de atender às necessidades e demandas dos consumi- } \\
\text { dores lançando ao mercado versões cada vez reformula- } \\
\text { das em modificações superficiais e com bastante apelo } \\
\text { visual, estético ou sensorial; }\end{array}$ \\
\hline O designer tecnológico & $\begin{array}{l}\text { Este tipo de formação profissional se baseia nas inova- } \\
\text { ções e avanços tecnológicos. Exemplos de conhecimentos } \\
\text { advindos da cibernética, da eletrônica e da informática } \\
\text { norteiam esta preparação. Por vezes, acompanha o mo- } \\
\text { delo consumista, mas também possui algumas inserções } \\
\text { politizadas como é o caso da Tecnologia Assistiva (T.A.). } \\
\text { O risco deste perfil é moldar profissionais tecnófilos ou } \\
\text { tecnomaníacos que acreditem que somente as soluções } \\
\text { com elevada complexidade tecnológica e de tecnologia } \\
\text { de ponta são as melhores, e para tanto, devem ser unica- } \\
\text { mente incentivadas; }\end{array}$ \\
\hline
\end{tabular}

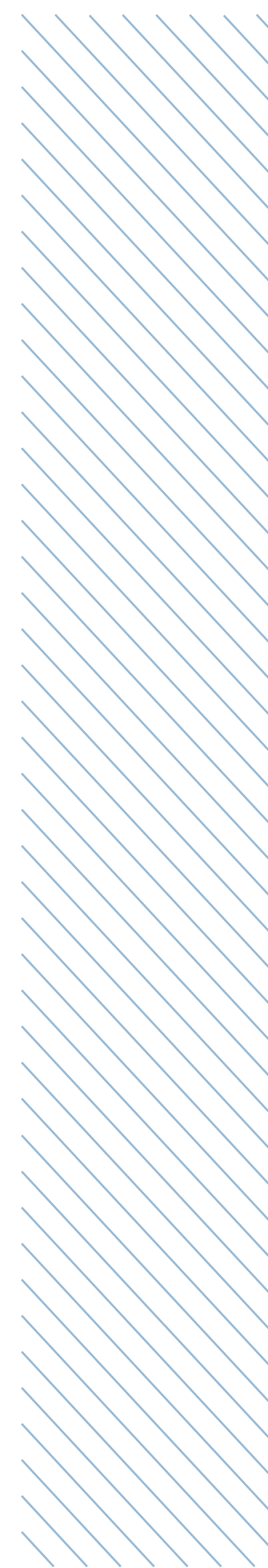




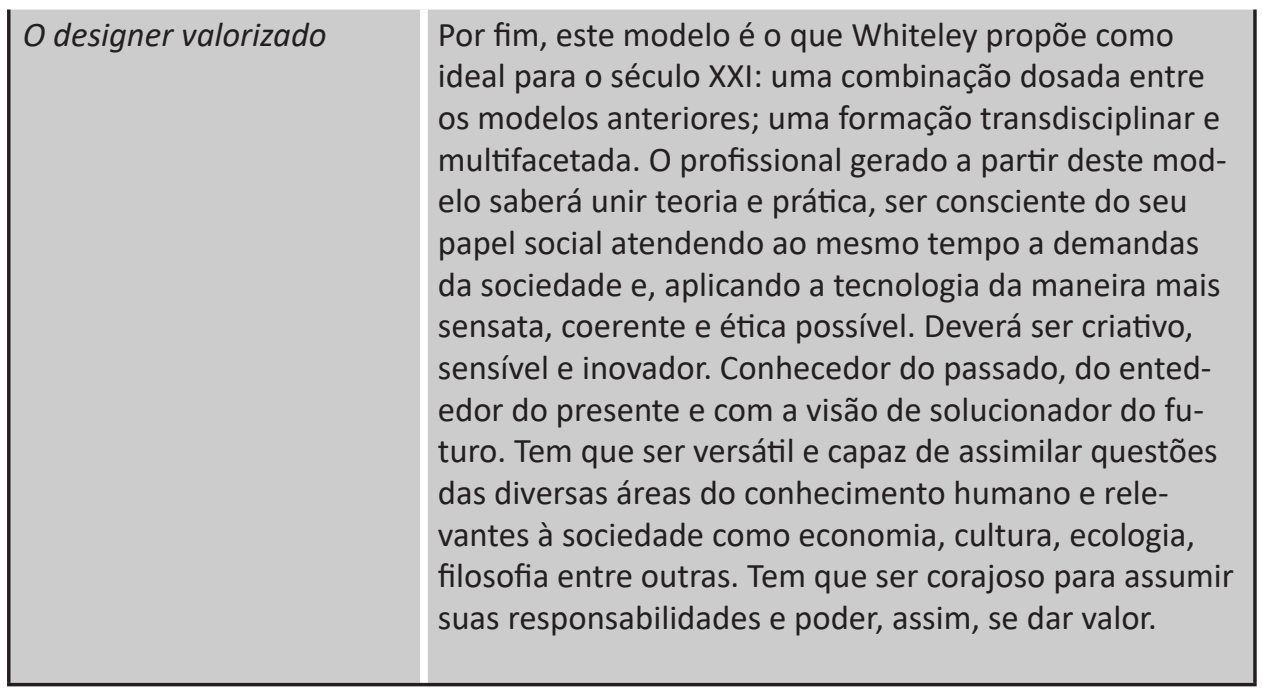

Fonte: Adaptado de Whiteley (1998)

\section{O MODELO GENERALISTA BRASILEIRO}

Embora Whiteley (1998) tenha tentado mapear os distintos perfis de formação educacional existe um que não fora relatado no cenário brasileiro, ou que talvez esteja implícito no próprio modelo valorizado, mas que se apresenta como uma nova tendência e realidade já instalada em vários centros educacionais no Brasil: o emprego do termo design tende a um generalismo no ensino e na educação, por conseguinte na profissão, resultando o designer generalista.

Depois que o Ministério da Educação e Cultura e o Conselho Nacional de Educação instituíram as mais novas Diretrizes Curriculares do MEC para a área de Desenho Industrial ${ }^{4}$, atualmente, conhecida por Design, as IES tiveram e ainda estão tendo que reformular suas grades e matrizes curriculares para se adequarem a esta nova realidade. A primeira dificuldade encontrada pelas IES refere-se ao fato das diretrizes - ainda que norteadoras - são muito vagas, imprecisas e dão margens a inúmeras interpretações. Tem-se que refletir, noutra ocasião, se a imprecisão das diretrizes curriculares se configura de modo salutar ou prejudicial.

O que vem ao caso é que as novas Diretrizes Curriculares do MEC para a área partem do pressuposto de que o profissional graduado deverá ter uma preparação mais holística e menos específica como se configurava em outras épocas: as conhecidas ênfases em Projeto do Produto ou Programação Visual deverão sair do cenário e dar origem a uma graduação generalista.

Esta configuração se dá por se acreditar em um profissional mais dinâmico, completo, diversificado e que possa ter a capacidade de moldar-se diante das demandas do mercado atual. Para isto, se torna imperiosa a existência de grades 
curriculares mais flexíveis. A intenção é louvável, mas possui muitas armadilhas que se apresentam principalmente diante do processo de graduação.

A analogia que se estabelece é a seguinte: imagina-se tal estratégia ser direcionada e aplicada nas Engenharias, outra área projetual. Atualmente, o ensino em engenharia se comporta separado por ênfases, ou seja, os cursos são ofertados a partir de especificações de subáreas: i) Engenharia Elétrica; ii) Engenharia Civil; iii) Engenharia Mecânica; iv) Engenharia Química; v) Engenharia de Produção entre outras. Será que se essa filosofia generalista fosse também aplicada às engenharias haveria perda ou ganho no ensino e na formação do profissional? Bem, deixa-se o questionamento para os próprios engenheiros refletirem se isto ocorrer um dia, mas com aqueles poucos que se tem mantido diálogo não se percebe boas impressões acerca dessa suposição. Dificilmente, um suposto engenheiro generalista estará preparado para tamanha empreitada, pois as áreas do conhecimento e suas aplicações são distintas, complexas e específicas. Certamente, segundo alguns deles, haveria comprometimentos sérios para os profissionais e para a própria área da Engenharia caso isto viesse a acontecer.

Pois bem, o mesmo raciocínio deve ser transportado para o Design. Imaginou-se em propor uma graduação generalista e, com a pós-graduação, os profissionais buscarem posteriormente as suas ênfases e especificidades. A estratégia faz sentido, porém desde que o nível e a qualidade na graduação não sejam interferidos. E o que se tem visto na prática, pela experiência na educação, na gestão e na avaliação de cursos - por parte da participação em Comissões de Avaliação de Cursos designadas pelo MEC/INEP/SINAES - ou, em contato com as grades e matrizes curriculares generalistas dos cursos mais recentes se têm demonstrado algumas preocupações:

a) Primeiro: Uma formação generalista em design amplia-se demais o universo de atuação, por conseguinte, exige-se um número maior de componentes curriculares de diversas e ecléticas abordagens;

b) Segundo: Essa modalidade de formação promete uma preparação holística, mas não embasa o candidato à profissão específica em área alguma. O que se apresenta como uma promessa de um "poderoso" profissional, apto para qualquer situação projetual finda em uma formação básica, superficial, limitada e frustrante a poucas experiências projetuais;

c) Terceiro: As grades e matrizes curriculares se transformam e terminam pulverizadas em diversas áreas de maneira bastante superficial sem se aprofundar em especialidade alguma;

d) Quarto: o modelo generalista permite, em uma mesma formação a mistura das práticas artesanais com as seriadas, algo difícil de ser 
equacionado com a projetação e produção industrial de produtos;

e) Quinto: As áreas e ênfases distintas, a saber, produto, moda, gráfico e interiores possuem uma pluralidade de conhecimentos tamanha que se torna, no mínimo arriscada para não se mencionar inviável uma formação em apenas quatro anos, mesmo que isso ocorra superficialmente. Supondo, por exemplo, que projeto de produto pode ser desdobrado em projeto de brinquedos, de móveis, de máquinas e implementos agrícolas, de ferramentas, de eletrodomésticos, de eletrônicos, de veículos de transporte, dentre outros, e que para cada segmento existem determinadas especificidades imaginem quando adicionadas às outras especificidades da moda, do gráfico e de interiores;

f) Sexto: Para se adequar a carga horária mínima de 2.400 horas, determinada pelas DCNs em Design, isto significa dizer se aproximar ao máximo dela para se evitarem currículos e carga horária extensa demais, as IES são forçadas a reduzir a carga horária nos componentes curriculares. Isto acarreta em problemas didático-pedagógicos, principalmente, para os componentes projetuais, práticos e do exercício da profissão produzindo uma geração de designers extremamente teóricos;

g) Sétimo: A formação generalista causa um problema para as instituições de ensino uma vez que precisam montar estruturas e laboratórios voltados às experimentações e práticas generalistas, ou seja, necessitam da oferta de espaços físicos pedagógicos voltados ao ensino, à pesquisa e à extensão que permeiem moda, gráfico, interiores e produto.

h) Oitavo: A flexibilidade anunciada pode desencadear outros vários problemas exemplificados na falta de compreensão dos níveis de flexibilização pelas IES - mínima, ideal ou exagerada - ou, na falta de maturidade discente, normal para a faixa etária global registrada na graduação, para fazer suas escolhas de componentes curriculares;

i) Nono: O modelo generalista produz um cerceamento ao estilo próprio e individual dos estudantes. Cada indivíduo, de acordo com seu processo histórico e de vida tem um interesse maior, um jeito, um gosto, uma afinidade natural por moda, por gráfico, por interiores ou por projeto de produtos. Isso deve ser respeitado e não podado;

j) Décimo: Ao final de sua formação o futuro profissional se gradua com a sensação de fragilidade, superficialidade, sem autoestima, sem confiança em si mesmo e bastante receoso do que enfrentará pela frente. Tem-se presenciado profissionais bastante inseguros e indecisos sobre o seu futuro; 
k) Décimo primeiro: A ênfase anunciada, defendida e focada apenas na pós-graduação, como uma estratégia de especialização nas áreas não se sustenta, pois atinge somente uma pequena parte do contingente global de egressos dos cursos. A grande maioria do universo de egressos dos cursos de graduação se priva das oportunidades de continuar seus estudos com pós-graduação por inúmeros motivos.

Decididamente, já não se fazem mais desenhistas industriais como antigamente. Assemelha-se a uma "espécie" em extinção. Não se sabe, ou não se tem a certeza, porém, se isto é algo saudável ou prejudicial.

Faz-se pertinente, neste momento, salientar que este recorte a seguir foi direcionado apenas ao que tange à subárea Design de Produto 5 .

Ao resgatarem-se as antigas grades curriculares da área, quando ainda graduava-se com a titulação de "desenhista industrial" e, ao se comparar com as mais recentes grades generalistas de Design se pode assegurar, com raras exceções, que as primeiras qualificavam melhor os profissionais voltados ao projeto de produto que as últimas. Em linhas gerais isto pode ser constatado pela: i) redução da carga horária global; ii) redução da carga horária projetual, de metodologias e da prática projetuais e de outras habilidades inerentes à projetação; iii) extinção de componentes curriculares subsidiadores da preparação voltada ao projeto de produto, como matemática, cálculo básico, desenho geométrico, geometria gráfica bi e tridimensional, física, estruturas, mecanismos e sistemas de transmissão de movimentos, análise de produtos entre outras; iv) redução dos componentes curriculares sobre materiais e processos de fabricação; v) redução da importância à ergonomia do produto e de ergonomia de processos; vi) extinção de componentes sobre custos e planejamentos de produtos; vii) ausência de componentes sobre economia, modelos administrativos, gerenciais e industriais das empresas; viii) ausência de componentes sobre história do design industrial, das revoluções industriais, e do processo de industrialização no Brasil e na América Latina; ix) desaparecimento de conteúdos envolvendo legislação e ética profissional, dentre outros casos.

5 A subárea tratada está estritamente relacionada ao perfil profissional do primeiro autor deste artigo: i) graduação em Desenho Industrial/Projeto de Produto pela UFPE (1993); ii) mestrado no Programa de Pós-Graduação em Engenharia de Produção, área de concentração Projeto de Produto, pela Universidade Federal de Santa Maria (1998); iii) doutorado pelo Programa de Pós-Graduação em Design da UNESP, na área Desenho do Produto e linha de pesquisa Planejamento do Produto, entre 2011 e 2014. Ainda, devido a mais de duas décadas como profissional graduado e uma década e meia com ensino em cursos de Design e Design de Produto, como ex-gestor e excoordenador de cursos da área na Universidade Regional do Noroeste do Estado do Rio Grande do Sul e na Universidade do Oeste de Santa Catarina e, recentemente, na Universidade Federal de Pernambuco. Do mesmo modo, há uma década membro do Cadastro Nacional de Avaliadores do MEC, na área de Design, em particular, de Design de Produto. 
Estes e outros componentes curriculares foram eliminados para dar lugar a tantos outros que atendessem às áreas da moda, do gráfico e de interiores e, portanto, atingisse a configuração do generalismo anunciado.

Com base nesta constatação pode-se afirmar que uma grade ou matriz pedagógica generalista não supre às reais demandas, carências e necessidades de um profissional que esteja almejando atuar junto à indústria ou como autônomo especializado na projetação e no desenvolvimento de produtos industriais. Não supre porque a sua meta generalista exclui a especificidade. Porque os interesses da proposta generalista são de abordar, ao mesmo tempo, uma ecletividade de conhecimentos necessários, mas que ao mesmo tempo se constituem superficiais ao projeto gráfico, de produto, da moda e de interiores.

E quais seriam então as possibilidades de solução para estes problemas? Sim, porque urge uma solução rápida, imediata já que a cada ano centenas ou milhares de profissionais saem do ensino para servir ao mercado profissional e, consequentemente, à sociedade. Não se pode esperar mais por fenômenos naturais; imperiosa é a antecipação às circunstâncias. Pois bem: podem-se mencionar alguns indicativos de alternativas para esta problemática:

A- As realidades regionais no Brasil são bastante diversificadas para o modelo generalista. Quanto a isto, sabe-se que cada IES encontra-se inserida em um contexto local e regional peculiar, algo que deve ser respeitado e visto com bastante atenção no que tange ao atendimento de necessidades específicas de cada contexto social, cultural, econômico, tecnológico, ambiental etc.;

B- A formação generalista não deve ser a única opção para as instituições ofertarem seus serviços educacionais. Ou seja, as IES devem tem a possibilidade de escolha, sem sanções, entre ofertar um modelo generalista ou por ênfases. Pode acontecer, inclusive, que uma mesma IES tenha uma grade curricular generalista e outra com especialidade, desde que haja público ou na mesma grade ocorra um momento inicial de generalismo e, posteriormente, a especificidade nas ênfases como uma alternativa ao estudante;

C- Uma matriz ou grade curricular pode ter uma versatilidade entre momentos letivos generalistas e por especialidades. O planejamento do curso deve permitir que os acadêmicos tenham blocos de componentes curriculares mais amplos e blocos de componentes específicos, independentemente do seu tipo de oferta por semestres, períodos ou módulos;

D- Cada especialidade possui intrinsecamente um generalismo. Ou seja, uma proposta pedagógica de um curso de design de produto, assim como às demais - gráfico, moda e interiores - naturalmente qual- 
ificam um profissional para a generalidade. Se observarmos no caso de projetos de produto se pode dar destaque ao projeto de louças, de cutelaria e de talheres, de calçados, do vestuário e de acessórios, do mobiliário residencial, técnico-profissional e urbano, de brinquedos, de embalagens, de eletrodomésticos, de eletrônicos, de joalheria, de transporte de cargas e de pessoas, de sinalização, de estandes e divisórias, de componentes para construção, de máquinas, equipamentos, instrumentos e ferramentas de diversas aplicações - agrícola, médico-hospitalar, óptica, musicais, segurança etc., segundo Barroso Neto (1982, p.10). Somam-se a isto outras especificidades surgidas na área industrial durante as últimas décadas, decorrentes, inclusive de mudanças tecnológicas como a propagação de componentes eletrônicos em diversos segmentos industriais e os desdobramentos da informatização e virtualidade.

Como se pode verificar dificilmente, em quatro anos, dá-se conta da formação de um designer generalista que esteja verdadeiramente preparado para atuar em todos os diversos setores que sua especialidade comporta. Sob esta ótica, isto já se caracteriza um modelo generalista: a interpretação do generalismo é ambígua e bastante relativa: depende do ponto de vista de cada um, de cada IES, ou de cada entidade ou órgão durante o ato da análise ou da reflexão.

Talvez por esses e outros motivos muitas IES e cursos de Desenho Industrial ainda relutam em alterar suas grades e matrizes curriculares por perceberem que tais questões são graves e trazem implicações ao ensino projetual e à profissionalização daqueles projetistas de produtos industriais. Do mesmo modo, também relutam em alterar a nomenclatura para Design, Design de Produto ou até mesmo Design Industrial.

\section{CONSIDERAC̣ÕES FINAIS}

Como se podem constatar as questões relacionadas não somente à linguagem e à pedagogia da área de design estão longe de se chegar a um consenso. Entretanto, quanto mais se omitir de trazê-las ao debate e à reflexão mais tempo se levará para compreendê-las na sua profundidade, e desse modo, propor ações eficazes ao seu desenvolvimento.

O embate, a divergência de opiniões e o desdobramento de correntes antagônicas se fazem necessárias para a construção do conhecimento científico e para a evolução das áreas do saber humano. A própria sociedade democrática se baseia nesta premissa para adquirir estágios evolutivos mais adiantados.

Cabe aos meios de comunicação de massa, no caso a mídia impressa e digital, abrir de maneira democrática, espaços para as opiniões serem manifestadas, de forma transparente e com a mesma seriedade. 
Nesse sentido, o design ou o desenho industrial serão beneficiados quer seja no discurso teórico da academia quer seja no âmbito prático da profissão. Portanto, acredita-se que se fazem necessárias reflexões na área projetual, mesmo que de maneira inquieta, mas que provoquem novas leituras, quebras de paradigmas e releituras sobre os caminhos a se seguir.

\section{REFERÊNCIAS}

BARROSO NETO, Eduardo (Org.). Desenho industrial: desenvolvimento de produto: oferta brasileira de entidades de projeto e consultoria. Brasília: CNPq, 1982.

BONSIEPE, Gui; IIDA, Itiro. Bacharelismo em questão. AGITPROP Revista Brasileira de Design, São Paulo, Ano 5,n. 49, 2013. Disponível em: <http://www.agitprop.com.br/index.cfm?pag= ensaios_ det\&id=105\&Titulo=ensaios $>$. Acesso em: 3 maio 2013.

BRASIL. Ministério da Educação. Parecer CNE/CES no 329/2004, aprovado em 11 de setembro de 2004b. Disponível em: <http://portal.mec.gov.br/ cne/arquivos/pdf/2004/pces329_04.pdf>. Acesso em: 20 jun. 2011.

BRASIL. Ministério da Educação. Parecer CNE/CES 0195/2003. Diretrizes Curriculares Nacionais de Bacharelado em Design. Disponível em: $<$ http://portal.mec.gov.br/cne/arquivos/pdf/CES_0195.pdf>. Acesso em: 20 jun. 2011.

BRASIL. Ministério da Educação. Resolução do CNE/CES nำ5, de 8 de março de 2004. Diretrizes Curriculares Nacionais de Bacharelado em Design. 2004a. Disponível em: <http://portal.mec.gov.br/ cne/arquivos/ pdf/rces05_04.pdf>. Acesso em: 20 jun. 2011.

FREYRE, Gilberto. Casa Grande \& Senzala. 10. ed. Rio de Janeiro: José Olympio, 1961. t. 1.

GOMES, Luiz Vidal Negreiros. A linguagem do design no Brasil. Revista Brasileira de Desenho industrial, Comunicação Visual e Arquitetura de Interiores (Design \& Interiores), São Paulo, Ano 3, n. 16, p.142-143.Out., 1989.

Para Uma Filosofia do Desenho ou Desenhismo. Recife: Editora Universitária da UFPE, 1993.

. Desenhismo. 2 ed. Santa Maria: Editora da Universidade Federal de Santa Maria, 1996.

REDIG, Joaquim. No Mínimo: condições mínimas necessárias ao ensino do design. Santa Maria: Editora da Universidade Federal de Santa Maria, 
1993.

SILVA, Danilo Émmerson Nascimento. $O$ design industrial e as engenharias: uma possibilidade de integração por intermédio da Engenharia Reversa. Tese (Doutorado em Design) - Universidade Estadual Paulista, Bauru, 2014.

SOUZA, Pedro Luiz Pereira de. ESDI: biografia de uma ideia. Rio de Janeiro: EdUERJ, 1996.

WHITELEY, Nigel. O designer valorizado. Revista Arcos, v. 1, n. 1, 1998. Disponível em: <http://www.esdi.uerj.br/arcos/arcos-01/01-05.artigo_ nigel\%2863a75\%29.pdf>. Acesso em: 20 jun. 2011. 